\title{
Relationship between Serum and Brain Carotenoids, $\alpha$-Tocopherol, and Retinol Concentrations and Cognitive Performance in the Oldest Old from the Georgia Centenarian Study
}

\author{
Elizabeth J. Johnson, ${ }^{1}$ Rohini Vishwanathan, ${ }^{1}$ Mary Ann Johnson, ${ }^{2}$ \\ Dorothy B. Hausman, ${ }^{2}$ Adam Davey, ${ }^{3}$ Tammy M. Scott, ${ }^{1}$ Robert C. Green, ${ }^{4}$ \\ L. Stephen Miller, ${ }^{2}$ Marla Gearing, ${ }^{5}$ John Woodard, ${ }^{6}$ Peter T. Nelson, ${ }^{7}$ Hae-Yun Chung, \\ Wolfgang Schalch, ${ }^{9}$ Jonas Wittwer, ${ }^{9}$ and Leonard W. Poon ${ }^{2}$ \\ ${ }^{1}$ Jean Mayer US Department of Agriculture Human Nutrition Research Center on Aging at Tufts University, Boston, MA 02111, USA \\ ${ }^{2}$ University of Georgia-Athens, Athens, GA 30602, USA \\ ${ }^{3}$ Temple University, Philadelphia, PA 19122, USA \\ ${ }^{4}$ Harvard University, Boston, MA 02115, USA \\ ${ }^{5}$ Emory University, Atlanta, GA 30322, USA \\ ${ }^{6}$ Wayne State University, Detroit, MI 48202, USA \\ ${ }^{7}$ University of Kentucky, Lexington, KY 40536, USA \\ ${ }^{8}$ Yonsei University, Seoul 120-749, Republic of Korea \\ ${ }^{9}$ DSM Nutritional Products, CH-4002 Basel, Switzerland
}

Correspondence should be addressed to Elizabeth J. Johnson; elizabeth.johnson@tufts.edu

Received 4 January 2013; Revised 5 April 2013; Accepted 28 April 2013

Academic Editor: Paula Bickford

Copyright (C) 2013 Elizabeth J. Johnson et al. This is an open access article distributed under the Creative Commons Attribution License, which permits unrestricted use, distribution, and reproduction in any medium, provided the original work is properly cited.

Oxidative stress is involved in age-related cognitive decline. The dietary antioxidants, carotenoids, tocopherols, and vitamin A may play a role in the prevention or delay in cognitive decline. In this study, sera were obtained from 78 octogenarians and 220 centenarians from the Georgia Centenarian Study. Brain tissues were obtained from 47 centenarian decedents. Samples were analyzed for carotenoids, $\alpha$-tocopherol, and retinol using HPLC. Analyte concentrations were compared with cognitive tests designed to evaluate global cognition, dementia, depression and cognitive domains (memory, processing speed, attention, and executive functioning). Serum lutein, zeaxanthin, and $\beta$-carotene concentrations were most consistently related to better cognition $(P<0.05)$ in the whole population and in the centenarians. Only serum lutein was significantly related to better cognition in the octogenarians. In brain, lutein and $\beta$-carotene were related to cognition with lutein being consistently associated with a range of measures. There were fewer significant relationships for $\alpha$-tocopherol and a negative relationship between brain retinol concentrations and delayed recognition. These findings suggest that the status of certain carotenoids in the old may reflect their cognitive function. The protective effect may not be related to an antioxidant effect given that $\alpha$-tocopherol was less related to cognition than these carotenoids.

\section{Introduction}

Cognitive decline in the elderly is a significant public health issue. It has been estimated that the incidence of mild cognitive impairment (MCI) is approximately $19 \%$ in those younger than 75 years and $29 \%$ in those older than 85 years [1]. Further, $13 \%$ of people aged 65 years and older are afflicted with Alzheimer's disease. Studies in centenarians 
have reported considerable dementia, ranging from 42 to $100 \%[2,3]$. The number of individuals so affected is likely to increase given that the number of people over 65 years is rising. As with most age-related diseases, the most cost effective way to combat disease is through prevention. One possible strategy is nutrition intervention [4].

Fruit and vegetable intake has been associated with cognitive function [5-7]. For example, in a study of 13,388 women, it was found that total vegetable intake was significantly associated with reduced cognitive decline [8]. The strongest association was with greater intake of green leafy and cruciferous vegetables. Fruits and vegetables are major dietary sources of carotenoids. Carotenoids are a class of naturally occurring pigments that are synthesized by plants and produce the red, orange, and yellow colors of fruits and vegetables. Carotenoids are comprised of two subclasses: xanthophylls (lutein, zeaxanthin, and $\beta$-cryptoxanthin) and carotenes $(\alpha$-carotene, $\beta$-carotene, and lycopene). In the Nurses' Health Study, among nonsupplement users, women in the highest quartile of plasma carotenoids had better cognitive performance than those in the lowest quartile [9]. Research has shown that patients with MCI had decreased plasma levels of antioxidants, including carotenoids [10]. Given that dietary carotenoids function as both antioxidants and anti-inflammatory agents and that oxidative stress and inflammation are believed to be involved in the pathogenesis of cognitive decline [11-20], intake of these dietary components may hold promise in cognitive health for the elderly.

The first objective of this study was to evaluate the relationship between serum concentrations of carotenoids and cognitive function in subjects from the Georgian Centenarian Study, a population-based multidisciplinary study of octogenarians and centenarians conducted in Georgia (USA) [21].

Given that an intervention with lutein was reported to improve cognitive function in the elderly [22] and that compared to carotenes, xanthophylls are preferentially taken up into brain tissue [23], a second objective of this research was to evaluate the cross-sectional relationship between brain carotenoids and premortem measures of cognitive function in a subgroup of the centenarian participants. For both serum and brain tissues, $\alpha$-tocopherol was measured for comparison since it crosses the blood brain barrier and has antioxidant properties. Serum and brain retinol concentrations were measured because of the provitamin A activity of certain carotenoids.

This study provides a unique advantage of being able to assess the relationship between serum and brain carotenoids. If indeed serum concentrations of individual carotenoids reflect their levels in the brain and these brain carotenoids are related to better cognitive performance, serum carotenoid measures could be a useful tool for evaluating the benefits of dietary carotenoids to age-related cognitive health.

\section{Materials and Methods}

2.1. Study Population. The Georgia Centenarian Study (GCS) [21], a population-based multidisciplinary study conducted in 44 counties in northern Georgia (USA) from 2001 to
2009, was designed to identify and isolate longevity genes, neuropathology, functional capacity, and adaptational characteristics of centenarians [17]. Living status was classified as community dwelling or institutionalized where community dwelling included those living in private residences and institutionalized included individuals living in a skilled nursing facility or personal care home. The study involving serum analyses included 244 centenarians (defined in this study as age 98 yrs and older) and 80 octogenarians. The study involving brain tissue analyses included 47 centenarians who volunteered to donate their brain upon death. Subjects were recruited from the community, personal care homes, and skilled nursing facilities. The sample procedures and data collection methods have been described elsewhere [21].

In the analyses of serum, we excluded 2 octogenarians and 7 centenarians from whom we were unable to obtain sufficient serum for analysis. The final number of subjects with a complete dataset for serum analytes and cognitive function was 220 subjects in the centenarian group and 78 subjects in the octogenarian group.

Brain tissue was obtained from four regions of the brain: right cerebellum, right temporal cortex, and right and left frontal and occipital cortices from the subset of centenarians. Serum and tissues were stored at $-80^{\circ} \mathrm{C}$ until analysis.

2.2. Serum and Brain Carotenoids, $\alpha$-Tocopherols, and Retinoids Extraction. Serum was as described previously [24]. The brain extraction procedure was adapted from Park et al. [25] and has been described in detail by our laboratory [26].

2.3. HPLC Analysis for Carotenoid, Tocopherols, and Retinol. Serum and brain extracts were analyzed by HPLC (Alliance 26951 Waters, Milford, MA, USA) as previously described [24]. Using this method, cis lutein, all-trans lutein, cis zeaxanthin, all-trans zeaxanthin, cryptoxanthin, $\alpha$-carotene, 13-cis $\beta$-carotene, all-trans $\beta$-carotene, 9-cis $\beta$-carotene, cis lycopene, and trans lycopene were separated and detected at $455 \mathrm{~nm}$. $\alpha$-Tocopherol, and retinol were detected at 292 and $340 \mathrm{~nm}$, respectively. Using this method, the lower limit of detection was $0.2 \mathrm{pmol}$ for carotenoids, $2.7 \mathrm{pmol}$ for $\alpha$ tocopherol and $2.0 \mathrm{pmol}$ for retinol.

The analysis of serum and brain tissues was conducted without knowledge of values for the associated measures of cognition.

2.4. Measures of Cognitive Performance. Subjects underwent a battery of cognitive tests designed to evaluate global cognitive function, dementia, and depression as well as several cognitive domains including memory, processing speed, or attention and executive functioning (see Table S1 in the Supplementary Material available online at http://dx.doi.org/10.1155/2013/951786). The Geriatric Depression Scale-short form was administered to screen for depressive symptoms in the subjects [27]. Cognitive measures included the Mini-Mental State Examination (MMSE) [28], Global Deterioration Rating Scale (GDRS) [29], Severe Impairment Battery (SIB) [30], Fuld Object Memory Evaluation (FOME) [31], Wechsler Adult Intelligence Scale-III 
(WAIS-III) Similarities Subtest [32], Behavioral Dyscontrol Scale [33], and Controlled Oral Word Association Test (COWAT) [34].

For participants in the separate brain donation component, additional cognitive tests were administered every six months until mortality. These tests included the Consortium to Establish a Registry for Alzheimer's Disease (CERAD) neuropsychological battery, which is composed of five subtests derived from previously established cognitive tests (verbal fluency, Boston Naming Test, MMSE, Constructional Praxis, and Word List Memory) $[35,36]$. These subtests have been found to be valid and reliable measures of cognition in normal aging and in Alzheimer's disease [37]. Further, no differences were found between participants in the brain donation component of the GCS and the rest of the centenarian participants [38]. All of these tests or versions of them have been used and validated in aging research settings or have demonstrated sensitivity to health variables in epidemiological studies [39-42].

2.5. Covariates and Predictors. In the analyses involving serum, covariates and predictors included age (80-89 or $\geq 98 \mathrm{y}$ ), gender, and race (white or African American, by design). The proportion of participants from each age group recruited from skilled nursing facilities was based on estimates of the "institutionalized" population of the study area according to the 2000 US Census figures [21]. Residence status was not considered as a covariate because it was a potential suppressor variable. Fifteen percent of the octogenarians and $62 \%$ of the centenarians resided in skilled nursing facilities. The remaining "community dwelling" participants resided in private residences and personal care homes. In the analyses involving brain tissue, which involved centenarian decedents, $31 \%$ of the decedents had resided in skilled nursing facilities.

2.6. Statistical Analyses. Results are expressed as geometric means \pm SDs. Relationships between trans and cis isomers of individual carotenoids and cognition did not differ appreciably. Therefore, the total (trans + cis) was used in the analysis. Given that the purpose of our analyses was to increase the precision with which an association could be estimated following adjustment for variables associated with our criterion, but not our predictor, we chose to analyze relationships between carotenoids, $\alpha$-tocopherol, and retinol with cognitive measures using partial correlations. Thus, the partial correlation can provide an estimate of substantive interest but has the added advantage in that it does so in a standardized and easily interpretable metric. Statistical significance was set at $P<0.05$. All statistical analyses were performed using SAS version 9.0 (serum) and SPSS version 19.0 (brain).

2.6.1. Serum Analyses. Data were verified for normality (Shapiro-Wilk test) and, when necessary, were logtransformed for normal distribution before further statistical analysis. Chi-square test and Student's $t$-test were used to compare subject characteristics, serum carotenoid levels, and cognitive values between groups. Pearson's correlations were performed to identify associations between cognitive indices with age, sex, anthropometric variables, and other possible confounders. The associations between cognitive indices and serum carotenoids were determined by calculating partial Pearson's correlation coefficients adjusted for age, sex, body mass index (BMI), smoking, alcohol, diagnosed hypertension, and diabetes. For the centenarians, diagnosis of hypertension and diabetes was drawn from proxy, family, staff, or charts.

2.6.2. Brain Analyses. Data were analyzed for all 47 decedents together and also separately for decedents based on their premortem GDRS scores. The purpose was to determine differences between decedents who had intact cognitive function (GDRS $=1$ ), mild memory loss (GDRS $=2$ ), mild cognitive impairment (GDRS = 3), and dementia (GDRS > 3) before death. One-way ANOVA was used to determine differences in age, education, BMI and brain carotenoid, $\alpha$ tocopherol, and retinol concentrations between the GDRS groups. Chi-square tests were used for categorical variables, which included sex, race, living arrangement, smoking status, alcohol use, hypertension, and diabetes. Repeated measures ANOVA was used to determine differences in carotenoids, tocopherol, and retinol concentrations between the four regions of the brain. For frontal and occipital cortices, tissue from both the left and right lobes of the brain was obtained. For cerebellum and temporal cortices, tissue from only the right side of the brain was obtained. No differences were observed in carotenoid, tocopherol and retinol concentrations between the right and left lobes for ten decedents (data not shown). In order to maintain consistency, only the right lobe of the brain was analyzed for all decedents. Mean brain carotenoid, $\alpha$-tocopherol, and retinol concentrations were calculated for each decedent based on measures from the four regions of the brain (cerebellum frontal, occipital, and temporal cortices). These means were used for comparison of carotenoid, $\alpha$-tocopherol, and retinol profiles between the brain and serum and also to evaluate differences between brain concentrations of individual micronutrients. Partial correlation coefficients were determined in order to evaluate the relationship of carotenoids, $\alpha$-tocopherol, and retinol with different measures of cognitive function. Age, sex, education, diabetes, and hypertension were used as covariates since these variables have the strongest influence on cognitive function measures. Concentration of trans lutein and zeaxanthin in the cerebellum was significantly greater than the three cortical regions of the brain. In order to determine associations with cognitive indices, concentration of carotenoids in the temporal, frontal, and occipital cortices was averaged, and associations were evaluated with and without cerebellum carotenoids.

\section{Results}

\subsection{Serum Analytes and Cognition}

3.1.1. Subject Characteristics. The characteristics of the octogenarians and centenarians who provided serum are given in Table 1. A significantly greater proportion of the centenarians 
TABLE 1: Subject characteristics.

\begin{tabular}{|c|c|c|c|c|c|c|c|}
\hline & $\begin{array}{c}\geq 80 \text { to } \leq 89 y \\
(n=78)\end{array}$ & $\begin{array}{c}\geq 98 y \\
(n=220)\end{array}$ & $P$ value* & $\begin{array}{c}\text { Community } \\
\text { dwelling } \\
(n=150)\end{array}$ & $\begin{array}{l}\text { Institutionalized } \\
\quad(n=148)\end{array}$ & $P$ value* & $\begin{array}{c}\text { Total } \\
(n=298)\end{array}$ \\
\hline Age, yrs $($ mean $\pm S D)$ & $84.2 \pm 2.7$ & $100.4 \pm 1.9$ & & $93.3 \pm 8.3$ & $99.7 \pm 4.6$ & $<0.0001$ & $96.6 \pm 7.4$ \\
\hline Male : female & $27: 51$ & $36: 184$ & 0.0007 & $40: 110$ & $23: 125$ & 0.0187 & $63: 235$ \\
\hline $\begin{array}{l}\text { Community dwelling } \\
(n) \text { : institutionalized }(n)\end{array}$ & $66: 12$ & $84: 136$ & $<0.0001$ & - & - & & $150: 148$ \\
\hline Education, yrs (mean \pm SD) & $13.0 \pm 3.5$ & $10.6 \pm 3.8$ & $<0.0001$ & $12.1 \pm 3.7$ & $10.3 \pm 3.7$ & $<0.0001$ & $11.2 \pm 3.8$ \\
\hline $\begin{array}{l}\text { Body mass index }\left(\mathrm{kg} / \mathrm{m}^{2}\right) \\
(\text { mean } \pm \mathrm{SD})\end{array}$ & $25.5 \pm 4.8$ & $22.6 \pm 4.7$ & $<0.0001$ & $24.2 \pm 4.7$ & $22.5 \pm 4.8$ & 0.0059 & $23.3 \pm 4.8$ \\
\hline Smoking $(n)$ & & & $<0.0001$ & & & 0.035 & \\
\hline None & 33 & 156 & & 88 & 101 & & 189 \\
\hline Ex-smoker & 40 & 54 & & 53 & 41 & & 94 \\
\hline Current & 5 & 7 & & 9 & 3 & & 12 \\
\hline No information & 0 & 3 & & 0 & 3 & & 3 \\
\hline Alcohol use $(n)$ & & & $<0.0001$ & & & $<0.0001$ & \\
\hline None & 22 & 134 & & 67 & 89 & & 156 \\
\hline Ex-drinker & 27 & 45 & & 32 & 40 & & 72 \\
\hline Current & 29 & 39 & & 51 & 17 & & 68 \\
\hline No information & 0 & 2 & & 0 & 2 & & 2 \\
\hline Hypertension $(n)$ & & & 0.394 & & & 0.306 & \\
\hline Yes & 32 & 108 & & 66 & 74 & & 140 \\
\hline No & 45 & 109 & & 83 & 71 & & 154 \\
\hline No information & 1 & 3 & & 1 & 3 & & 4 \\
\hline
\end{tabular}

${ }^{*}$ Significant difference between groups. Means were compared using Student's $t$-test. Fisher's exact test was applied for categorical variables.

were women, institutionalized, and nonsmokers compared to the octogenarians $(P<0.001)$. Furthermore, the centenarians had significantly less education years, alcohol use, and BMI $(P<0.001)$. There was no difference in the prevalence of hypertension in these two age groups.

A greater proportion of the institutionalized subjects were women and nonsmokers compared to the community dwelling subjects $(P<0.02$ and 0.035 , resp., Table 1$)$. They were also significantly older than the community dwelling subjects $(P<0.001)$. The institutionalized subjects had significantly less education years, alcohol use, and BMI $(P<0.001)$. There was no difference in the prevalence of hypertension in these two groups.

\subsubsection{Serum Carotenoids, $\alpha$-Tocopherol, and Retinol Concen-} trations. Serum concentrations of individual carotenoids, $\alpha$ tocopherol and retinol are given in Table 2. Compared to the octogenarians, the centenarians had lower mean values for all carotenoids and $\alpha$-tocopherol, which was significantly different $(P<0.05)$ for all analytes except cis zeaxanthin and marginally significant for trans lutein $(P<0.075)$ and $\beta$ carotene $(P<0.084)$. Similarly, the institutionalized subjects had lower mean values for all carotenoids and $\alpha$-tocopherol which was significantly different $(P<0.05)$ for all analytes except for cryptoxanthin, $\alpha$-carotene, and $\beta$-carotene and marginally significant for trans zeaxanthin $(P<0.052)$.
Serum retinol values were neither significantly different between octogenarians and centenarians nor between community dwelling and institutionalized subjects.

3.1.3. Cognitive Function in Octogenarians and Centenarians. The cognitive function status of subjects from the Georgia Centenarian Study is found in Table S2 of the Supplementary Material. For all measures of cognitive function, mean values were significantly lower in the centenarians than in octogenarians $(P<0.0001)$ except for delayed recognition which was not different between the two groups. For all measures of cognitive function, the institutionalized subjects had significantly lower values than the community dwelling subjects $(P<0.0005)$.

3.1.4. Relationships between Serum Carotenoids, $\alpha$-Tocopherol, and Retinol and Cognitive Performance. In the total study population, serum lutein and zeaxanthin concentrations were most consistently related to better cognitive performance, with a significant correlation observed $(P<0.05)$ (Table 3$)$ for all cognitive measures except delayed recognition. It should be noted that none of the serum analytes were correlated with delayed recognition. Serum concentrations of $\beta$-carotene were also significantly correlated to most measures of cognitive function $(P<0.05)$ with the exception 
TABLE 2: Serum carotenoid, $\alpha$-tocopherol, and retinol concentrations in subjects from the Georgian Centenarian Study (mean \pm SD).

\begin{tabular}{|c|c|c|c|c|c|c|c|}
\hline $\begin{array}{l}\mathrm{nmol} / \mathrm{L} \text { (carotenoids) } \\
\mu \mathrm{mol} / \mathrm{L}(\alpha \text {-tocopherol, retinol) }\end{array}$ & $\begin{array}{c}\geq 80 \text { to } \leq 89 y \\
\quad(n=78)\end{array}$ & $\begin{array}{c}\geq 98 y \\
(n=220)\end{array}$ & $P$ value ${ }^{*}$ & $\begin{array}{c}\text { Community } \\
\text { dwelling } \\
(n=150)\end{array}$ & $\begin{array}{l}\text { Institutionalized } \\
\quad(n=148)\end{array}$ & $P$ value* & $\begin{array}{c}\text { Total } \\
(n=298)\end{array}$ \\
\hline Lutein, trans & $213 \pm 162$ & $199 \pm 177$ & 0.0753 & $223 \pm 199$ & $181 \pm 141$ & 0.0072 & $204 \pm 174$ \\
\hline Lutein, cis & $58 \pm 58$ & $53 \pm 65$ & 0.0006 & $63 \pm 77$ & $46 \pm 46$ & 0.0162 & $56 \pm 63$ \\
\hline Lutein, total & $316 \pm 255$ & $293 \pm 285$ & 0.0156 & $334 \pm 329$ & $265 \pm 207$ & 0.0116 & $300 \pm 276$ \\
\hline Zeaxanthin, trans & $47 \pm 23$ & $44 \pm 28$ & 0.0194 & $49 \pm 30$ & $42 \pm 23$ & 0.0516 & $46 \pm 26$ \\
\hline Zeaxanthin, cis & $5 \pm 16$ & $5 \pm 11$ & 0.6388 & $7 \pm 14$ & $4 \pm 9$ & 0.0764 & $5 \pm 12$ \\
\hline Zeaxanthin, total & $53 \pm 32$ & $49 \pm 37$ & 0.0355 & $56 \pm 40$ & $46 \pm 28$ & 0.0195 & $51 \pm 35$ \\
\hline Cryptoxanthin & $159 \pm 105$ & $148 \pm 125$ & 0.0362 & $166 \pm 137$ & $134 \pm 96$ & 0.3174 & $150 \pm 119$ \\
\hline$\alpha$-Carotene & $80 \pm 110$ & $63 \pm 61$ & 0.0122 & $71 \pm 93$ & $63 \pm 54$ & 0.6972 & $67 \pm 76$ \\
\hline$\beta$-Carotene, trans & $547 \pm 836$ & $443 \pm 419$ & 0.2200 & $542 \pm 670$ & $398 \pm 406$ & 0.0056 & $471 \pm 558$ \\
\hline$\beta$-Carotene, cis & $20 \pm 26$ & $17 \pm 22$ & 0.6538 & $19 \pm 26$ & $17 \pm 20$ & 0.5322 & $19 \pm 22$ \\
\hline$\beta$-Carotene, total & $568 \pm 855$ & $460 \pm 432$ & 0.0839 & $560 \pm 69$ & $415 \pm 419$ & 0.0039 & $488 \pm 573$ \\
\hline Lycopene, trans & $240 \pm 181$ & $138 \pm 119$ & $<0.0001$ & $199 \pm 166$ & $130 \pm 112$ & $<0.0001$ & $164 \pm 145$ \\
\hline Lycopene, cis & $389 \pm 277$ & $231 \pm 227$ & $<0.0001$ & $324 \pm 276$ & $220 \pm 212$ & 0.0003 & $272 \pm 251$ \\
\hline Lycopene, total & $629 \pm 443$ & $369 \pm 337$ & $<0.0001$ & $523 \pm 430$ & $348 \pm 309$ & 0.0003 & $436 \pm 384$ \\
\hline$\alpha$-Tocopherol & $31.9 \pm 16.8$ & $25.5 \pm 12.9$ & 0.0011 & $29.6 \pm 15.0$ & $24.8 \pm 13.2$ & 0.0016 & $29.2 \pm 14.3$ \\
\hline Retinol & $2.14 \pm 0.07$ & $1.84 \pm 0.62$ & 0.449 & $2.00 \pm 0.64$ & $1.83 \pm 0.59$ & 0.247 & $1.92 \pm 0.62$ \\
\hline
\end{tabular}

${ }^{*}$ Significant difference between groups. Means were compared using Student's $t$-test. Chi-square analysis was applied for categorical variables.

TABLE 3: Partial correlation coefficients between cognition indices and serum carotenoids, $\alpha$-tocopherol, and retinol in octogenarians and centenarians from the Georgia Centenarian Study (adjusted w/age, sex, education years, BMI, smoking, alcohol, hypertension, and diabetes, $n=298)$.

\begin{tabular}{|c|c|c|c|c|c|c|c|c|}
\hline & $\begin{array}{c}\text { Mini- } \\
\text { Mental } \\
\text { State Exam }\end{array}$ & $\begin{array}{l}\text { Global Dete- } \\
\text { rioration } \\
\text { Rating Scale }\end{array}$ & $\begin{array}{c}\text { FOME }^{1} \\
\text { delayed } \\
\text { recall }\end{array}$ & $\begin{array}{c}\text { FOME } \\
\text { delayed } \\
\text { recognition }\end{array}$ & $\begin{array}{l}\text { FOME } \\
\text { delayed } \\
\text { retention }\end{array}$ & $\begin{array}{c}\text { Controlled } \\
\text { Oral Word } \\
\text { Association } \\
\text { Test }\end{array}$ & $\begin{array}{l}\text { WAIS-III } \\
\text { Similarities } \\
\text { Subtest }^{2}\end{array}$ & $\begin{array}{c}\text { Behavioral } \\
\text { Dyscontrol } \\
\text { Scale Total } \\
\text { Score }\end{array}$ \\
\hline Lutein, $($ trans + cis $)$ & 0.114 & $-0.350^{\mathrm{a}}$ & $0.177^{\mathrm{b}}$ & 0.009 & 0.114 & $0.148^{\mathrm{c}}$ & $0.244^{\mathrm{a}}$ & $0.180^{\mathrm{b}}$ \\
\hline Zeaxanthin, $($ trans $+c i s)$ & $0.128^{c}$ & $-0.236^{\mathrm{a}}$ & $0.134^{\mathrm{c}}$ & 0.069 & $0.146^{\mathrm{c}}$ & $0.169^{\mathrm{b}}$ & $0.184^{\mathrm{b}}$ & $0.196^{\mathrm{b}}$ \\
\hline Cryptoxanthin & 0.026 & -0.096 & 0.054 & 0.002 & 0.035 & 0.031 & $0.129^{c}$ & 0.045 \\
\hline$\alpha$-Carotene & -0.014 & -0.068 & 0.017 & -0.029 & 0.009 & 0.015 & 0.074 & 0.029 \\
\hline$\beta$-Carotene, $($ trans + cis $)$ & 0.072 & $-0.244^{\mathrm{a}}$ & $0.173^{\mathrm{b}}$ & 0.082 & $0.168^{\mathrm{b}}$ & $0.186^{\mathrm{b}}$ & $0.144^{\mathrm{c}}$ & $0.227^{\mathrm{a}}$ \\
\hline Lycopene, $($ trans + cis $)$ & -0.014 & $-0.142^{\mathrm{c}}$ & -0.017 & -0.033 & 0.014 & 0.017 & 0.108 & 0.044 \\
\hline$\alpha$-Tocopherol & 0.118 & $-0.194^{\mathrm{b}}$ & 0.097 & 0.097 & $0.145^{\mathrm{c}}$ & 0.106 & $0.121^{\mathrm{c}}$ & $0.200^{\mathrm{b}}$ \\
\hline Retinol & 0.089 & -0.078 & 0.113 & 0.022 & 0.105 & 0.006 & 0.045 & 0.116 \\
\hline
\end{tabular}

FOME: Fuld Object Memory Evaluation; ${ }^{2}$ WAIS-III Similarities Subtest: Wechsler Adult Intelligence Scale-III Similarities Subtest.

Significantly related $(P<):{ }^{\mathrm{a}} 0.001 ;{ }^{\mathrm{b}} 0.01,{ }^{\mathrm{c}} 0.05$.

of the MMSE and delayed recognition (Table 3). Serum $\alpha$ tocopherol concentrations were inversely related to dementia severity (Geriatric Deterioration Scale) $(P<0.01)$ and positively related to delayed retention, abstract reasoning, and the Behavioral Dyscontrol Scale $(P<0.05)$. Higher serum lycopene concentrations were only related to a lower dementia severity $(P<0.01)$. Serum cryptoxanthin was only related to the WAIS-III test $(P<0.05$, Table 5$)$. Serum retinol concentrations were not related to any of the cognitive function measures.

In the octogenarians, serum lutein concentrations were significantly related to measures of global cognition, lower dementia severity, and executive function $(P<0.05)$ (Table
S3 of the Supplementary Material). In this age group, serum cryptoxanthin was inversely related to delayed recall $(P<$ $0.05)$. There were no other significant relationships. In the centenarians, none of the serum carotenoids or $\alpha$-tocopherol were related to global cognition or delayed recognition. Higher concentrations of lutein, zeaxanthin, $\beta$-carotene, and $\alpha$-tocopherol were significantly related to lower dementia severity $(P<0.05)$. Additional significant relationships were found between lutein and abstract reasoning, between $\beta$ carotene and verbal fluency (Controlled Oral Word Association Test), WAIS-III and executive function, between $\alpha$ tocopherol and executive function, and between retinol and delayed recall $(P<0.05)$. 
TABLE 4: Mean ( \pm SEM) concentrations of carotenoids, $\alpha$-tocopherol, and retinol in the cerebellum, frontal, occipital, and temporal cortices $(n=47)$.

\begin{tabular}{|c|c|c|c|c|}
\hline Analyte (pmol/g) & Cerebellum & Frontal cortex & Occipital cortex & Temporal cortex \\
\hline Lutein, cis & $6.5 \pm 1.4^{\mathrm{a}}$ & $4.0 \pm 1.6^{\mathrm{a}, \mathrm{b}}$ & $2.8 \pm 0.7^{\mathrm{b}}$ & $3.1 \pm 0.8^{\mathrm{b}}$ \\
\hline Lutein, trans & $169.8 \pm 15.5^{\mathrm{a}}$ & $78.7 \pm 7.6^{\mathrm{b}}$ & $91.8 \pm 9.1^{\mathrm{b}}$ & $81.7 \pm 7.8^{\mathrm{b}}$ \\
\hline Total Lutein $($ cis + trans $)$ & $176.4 \pm 16.6^{\mathrm{a}}$ & $82.7 \pm 8.0^{\mathrm{b}}$ & $94.6 \pm 9.6^{c}$ & $84.8 \pm 8.4^{\mathrm{b}, \mathrm{c}}$ \\
\hline Zeaxanthin, trans & $52.9 \pm 4.3^{\mathrm{a}}$ & $25.9 \pm 1.9^{\mathrm{b}}$ & $30.0 \pm 2.0^{c}$ & $27.8 \pm 2.0^{\mathrm{b}, \mathrm{c}}$ \\
\hline Cryptoxanthin $(\alpha+\beta)$ & $75.8 \pm 13.7^{\mathrm{a}, \mathrm{b}}$ & $63.4 \pm 10.2^{\mathrm{a}}$ & $93.4 \pm 15.6^{\mathrm{b}}$ & $60.7 \pm 9.4^{\mathrm{a}}$ \\
\hline$\beta$-Carotene, trans & $59.8 \pm 5.7^{\mathrm{a}}$ & $60.8 \pm 6.4^{\mathrm{a}}$ & $70.2 \pm 6.9^{\mathrm{b}}$ & $51.8 \pm 4.3^{\mathrm{a}}$ \\
\hline$\beta$-Carotene, 9-cis & $12.0 \pm 1.5^{\mathrm{a}}$ & $13.5 \pm 1.8^{\mathrm{a}}$ & $16.9 \pm 2.0^{\mathrm{b}}$ & $13.1 \pm 1.9^{\mathrm{a}, \mathrm{b}}$ \\
\hline Lycopene, trans & $26.3 \pm 4.4$ & $21.0 \pm 3.7$ & $21.9 \pm 3.6$ & $19.9 \pm 3.2$ \\
\hline$\alpha$-Tocopherol & $43475 \pm 1877^{\mathrm{a}}$ & $67027 \pm 2992^{\mathrm{b}, \mathrm{c}}$ & $72971 \pm 2442^{\mathrm{c}}$ & $65521 \pm 1940^{\mathrm{b}}$ \\
\hline Retinol & $472 \pm 24^{\mathrm{a}}$ & $615 \pm 42^{\mathrm{b}}$ & $676 \pm 43^{\mathrm{b}, \mathrm{c}}$ & $768 \pm 54^{\mathrm{c}}$ \\
\hline
\end{tabular}

Means not sharing a common superscript in the same row are significantly different at $P<0.05$ (repeated measures ANOVA with Bonferroni adjustment for multiple comparisons).

TABLE 5: Mean $( \pm$ SEM) concentrations of carotenoids, $\alpha$-tocopherol, and retinol in the brain (average of cerebellum, frontal, occipital, and temporal cortices) based on premortem GDRS scores in decedents with normal cognitive function (GDRS =1), subjective mild memory loss $(\mathrm{GDRS}=2)$, and mild cognitive impairment $(\mathrm{GDRS}=3)$.

\begin{tabular}{lccc}
\hline pmol/g & & ${\text { Global deterioration scale (GDRS })^{\mathrm{a}}}$ & $3(n=11)$ \\
\hline Lutein, trans & $1(n=5)$ & $2(n=7)$ & $67 \pm 14^{\mathrm{c}}$ \\
Total lutein (cis + trans) & $133 \pm 21^{\mathrm{b}}$ & $124 \pm 17^{\mathrm{b}, \mathrm{c}}$ & $68 \pm 15^{\mathrm{c}}$ \\
Zeaxanthin, trans & $145 \pm 22^{\mathrm{b}}$ & $43 \pm 18^{\mathrm{b}, \mathrm{c}}$ & $25.9 \pm 5.0$ \\
Cryptoxanthin & $45.0 \pm 7.5$ & $63.2 \pm 6.3$ & $57.2 \pm 15.1$ \\
$\beta$-Carotene, trans & $90.1 \pm 22.4$ & $48.0 \pm 8.9^{\mathrm{b}, \mathrm{c}}$ & $39.5 \pm 7.1^{\mathrm{c}}$ \\
Lycopene, trans & $77.6 \pm 10.5^{\mathrm{b}}$ & $26.1 \pm 7.6$ & $16.4 \pm 6.1$ \\
$\gamma^{-}$-Tocopherol & $37.0 \pm 9.0$ & $2129 \pm 313$ & $1518 \pm 249$ \\
$\alpha$-Tocopherol & $1609 \pm 370$ & $63205 \pm 4475$ & $60028 \pm 3570$ \\
Retinol & $67408 \pm 5295$ & $530 \pm 92$ & $691 \pm 74$ \\
\hline
\end{tabular}

aDRS = 1: no subjective complaints or objective evidence of memory deficits; GDRS = 2: subject complaints, but no objective evidence of memory deficits; GDRS $=3$ : mild cognitive impairment.

Means not sharing a common superscript in the same row are significantly different at $P<0.05$ (univariate ANOVA with Bonferroni adjustment for multiple comparisons).

In the community dwelling subjects, serum zeaxanthin had significant relationships with most measures of cognitive function (Supplementary Material, Table S4), with higher concentrations being significantly related to global cognitive performance, lower dementia severity, delayed recall and retention, verbal fluency, and concept formation/abstraction $(P<0.05)$. Higher serum lutein was significantly related to global cognitive function, lower dementia severity, and delayed recall and retention $(P<0.05)$. Other significant relationships were found between higher $\beta$-carotene concentrations and lower dementia, delayed recall and retention, and verbal fluency and executive function $(P<0.05)$. In the community dwelling subjects, $\alpha$-tocopherol was only significantly related to executive function $(P<0.05)$. There were no significant relationships found between cryptoxanthin, $\alpha$ carotene and retinol and cognitive measures.

Fewer significant relationships were found between serum analytes and cognitive measures in the institutionalized subjects. In this group, significant relationships were found between lower dementia severity and serum concentrations of lutein, zeaxanthin, $\beta$-carotene, and $\alpha$-tocopherol.
Serum lutein, zeaxanthin, cryptoxanthin, and $\alpha$-carotene were significantly related to concept formation/abstraction $(P<0.05)$. Lutein, zeaxanthin, $\beta$-carotene, $\alpha$-tocopherol and retinol were significantly related to executive function $(P<0.05)$.

\subsection{Brain Analytes and Cognition}

3.2.1. Subject Characteristics. The characteristics of the cententarian population for which brain tissues were available are described in Table S5 of the Supplementary Material. Of the 47 decedents, five had normal cognitive function (GDRS $=1)$, seven had subjective mild memory loss (GDRS $=2$ ), and eleven had MCI (GDRS = 3). There were 24 decedents who had different stages of dementia (GDRS 4 to 7). Subjects with dementia were slightly older than those with intact cognitive function. However, the differences were not significant. Eighty-nine percent of the decedents were females, and $89 \%$ were Caucasians. Race/ethnicity, sex, education, BMI, smoking status, and alcohol use did not differ by GDRS status. A greater proportion of the 


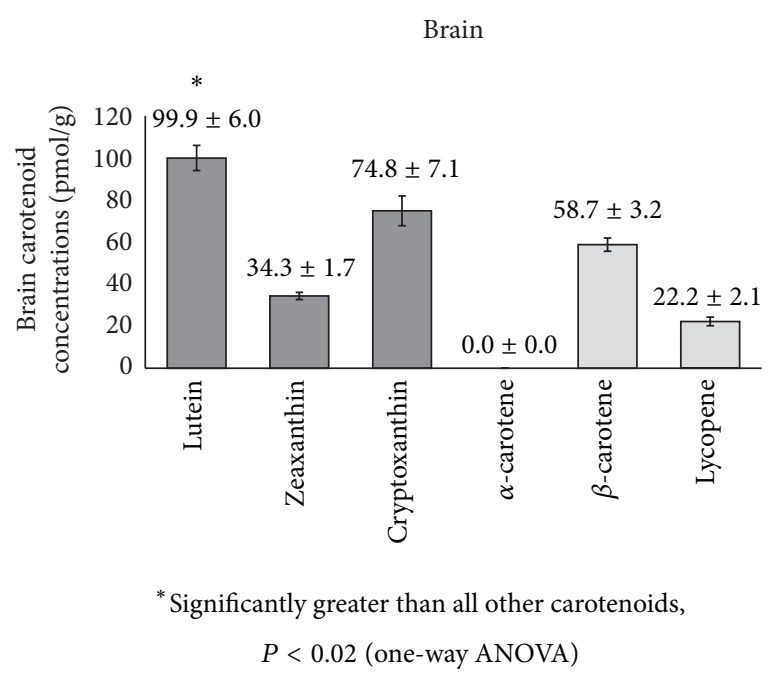

(a)

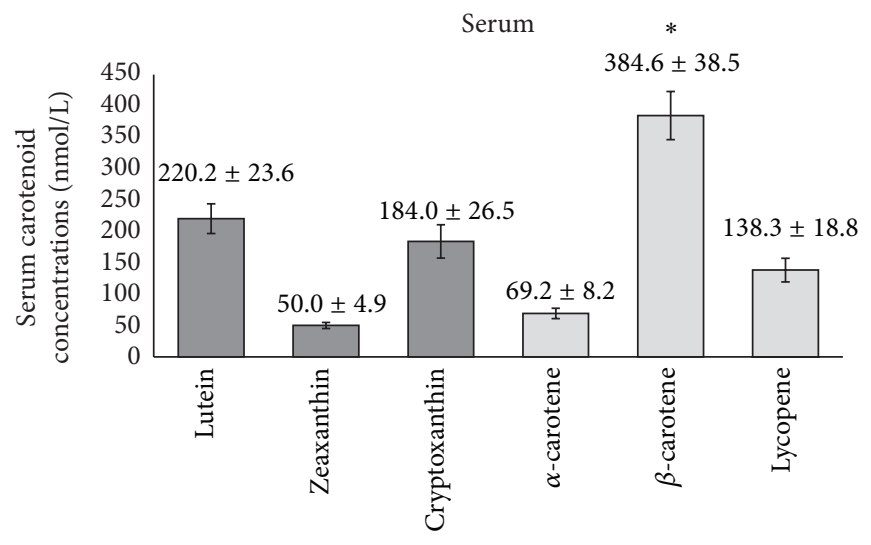

* Significantly greater than all other carotenoids, $P<0.0001$ (one-way ANOVA)

(b)

Figure 1: Mean ( \pm SEM) concentrations of carotenoids (trans isomers) in the brain (average of cerebellum frontal serum, occipital, and temporal cortices) of decedents from the Georgia Centenarian Study $(n=42)$. Dark gray bars indicate xanthophyll carotenoids. Light gray bars indicate carotenes.

decedents were institutionalized; however, the differences between institutionalized and community dwelling subjects were not statistically significant. The prevalence of diabetes and hypertension did not differ between these two groups.

\subsubsection{Brain Carotenoid, $\alpha$-Tocopherol, and Retinol Concentra-} tions. The mean concentration of individual carotenoids, $\alpha$ tocopherol, and retinol in the cerebellum, frontal, occipital, and temporal cortices from the 47 decedents is shown in Table 4. The range of values for carotenoids was $0-661 \mathrm{pmol} / \mathrm{g}$. For $\alpha$-tocopherol, the range was 22,979$137,576 \mathrm{pmol} / \mathrm{g}$ and for retinol 202-2,233 $\mathrm{pmol} / \mathrm{g}$. Mean lutein and zeaxanthin concentrations were significantly greater in the cerebellum compared to the frontal, occipital, and temporal cortices. Concentrations of cryptoxanthin and $\beta$ carotene the were highest in the occipital cortex and were significantly different from the frontal and temporal cortices. $\alpha$-Carotene was not detected in these brain tissues. Contrary to lutein and zeaxanthin, concentrations of $\alpha$-tocopherol and retinol were the lowest in the cerebellum and significantly different from all three cortical regions.

The proportion of cis to trans isomers was much lower in the brain than in the serum. The ratio of cis to trans lutein and $\beta$-carotene was $\sim 0.25$ in the serum while in the brain it was only $\sim 0.04$. Although present in the serum, cis isomers of zeaxanthin and lycopene were not detected in any of the brain regions analyzed. Of note is that brain carotenoids were significantly related to their concentrations in serum $(P<0.01$ for all, except cis lutein: $P<0.05)$. $\alpha$-Tocopherol concentrations in the cortices were also significantly related to serum concentrations $(P<0.01)$. However, $\alpha$-tocopherol in the cerebellum was not. Retinol concentrations in all brain regions were not related to serum retinol concentrations.

Figure 1 shows the mean carotenoid (trans isomers) concentrations in the brain and matched serum for the decedents that had both serum and brain tissue. In the brain, xanthophylls (lutein, zeaxanthin, and cryptoxanthin) accounted for $72 \%$ of total carotenoids, of which lutein accounted for $34 \%$ of the total and was significantly greater than all other carotenoids $(P<0.02)$. The proportion of carotenes ( $\alpha$-carotene, $\beta$-carotene, and lycopene) was higher than xanthophylls in serum, accounting for $57 \%$ of the total carotenoids of which $\beta$-carotene accounted for $37 \%$ of the total and was significantly greater than all other carotenoids $(P<0.0001)$.

3.2.3. Brain Carotenoids, $\alpha$-Tocopherol, and Retinol Concentrations in Decedents with Intact Cognitive Function, Mild Memory Loss, and MCI. The mean brain concentrations of carotenoids, $\alpha$-tocopherol, and retinol for decedents with GDRS $\leq 3$ and GDRS $>3$ were not significantly different (data not shown) with the exception of 9 cis $\beta$-carotene which was significantly higher in dementia $(17 \pm 3.1$ versus $9,8 \pm$ $1.7 \mathrm{pmol} / \mathrm{g}$ ).

Table 5 shows brain carotenoids, $\alpha$-tocopherol, and retinol concentrations in decedents with normal cognitive function, mild memory loss, and MCI. Due to the advanced pathological changes in brain and significant reduction in brain volume associated with dementia, decedents with dementia were not included in this analysis [43]. Additionally, the neuropathological and neurobiological brain changes associated with MCI are quantitatively less than those associated with dementia [44]. Mean concentrations of all carotenoids were found to progressively decrease with increasing GDRS scores from 1 to 3 . However, only the differences in lutein and $\beta$-carotene concentrations between subjects with normal cognitive function and MCI were statistically significant $(P<0.05)$. When data were adjusted for age, sex, education, diabetes, and hypertension, only the differences observed in lutein concentrations between the 
TABLE 6: Cross-sectional relationship between concentrations of carotenoids, $\alpha$-tocopherol, and retinol in the cortex (average concentrations of the frontal, occipital, and temporal cortices) and premortem measures of cognitive function in subjects with normal cognitive function, mild memory loss, and MCI who completed the cognitive function tests a year prior their death $(n=21)$.

\begin{tabular}{lccccccc}
\hline & MMSE & FOME recognition & SIB & COWAT & BDS & CERAD verbal fluency & CERAD Boston naming test \\
\hline Lutein $($ trans + cis $)$ & $0.494^{\mathrm{a}}$ & -0.297 & 0.076 & 0.142 & 0.459 & 0.455 & $0.572^{\mathrm{a}}$ \\
Zeaxanthin & 0.439 & -0.281 & 0.139 & 0.177 & 0.286 & $0.461^{\mathrm{a}}$ & 0.207 \\
Cryptoxanthin & -0.056 & 0.325 & -0.021 & 0.152 & 0.046 & 0.302 & 0.084 \\
$\beta$-Carotene, trans & 0.265 & -0.010 & -0.014 & 0.269 & 0.137 & 0.265 & 0.008 \\
Lycopene, trans & 0.124 & -0.003 & 0.132 & 0.067 & -0.085 & 0.065 & 0.275 \\
$\alpha$-Tocopherol & 0.393 & -0.295 & $0.568^{\mathrm{a}}$ & $0.637^{\mathrm{a}}$ & 0.434 & 0.328 & 0.165 \\
Retinol & 0.161 & -0.456 & 0.168 & 0.400 & 0.067 & 0.108 & -0.307 \\
\hline
\end{tabular}

Values are partial correlation coefficients adjusted for sex, education, diabetes, and hypertension.

${ }^{\mathrm{a}} P \leq 0.05$.

MMSE: Mini-Mental State Examination; FOME: Fuld Object Memory Evaluation; SIB: Severe Impairment Battery; COWAT: Controlled Oral Word Association Test; BDS: Behavioral Dyscontrol Scale; CERAD: Consortium to Establish a Registry for Alzheimer’s Disease.

two groups remained significant $(P<0.05)$. Mean brain retinol concentration was not significantly different between individuals with MCI and normal cognitive function. Similar results were obtained when concentrations of carotenoids, $\alpha$ tocopherol, and retinol in the cerebellum and cortex (average of frontal, temporal, and occipital) were analyzed separately. Data corrected for covariates are not reported due to the small sample size in each GDRS subgroup.

3.2.4. Relationship between Brain Carotenoids, $\alpha$-Tocopherol, and Retinol and Cognitive Function Measures. Of the 23 decedents with normal cognitive function, mild memory loss, and MCI, data for 21 subjects whose cognitive function tests were performed within one year $(4.3 \pm 2.8 \mathrm{mo}$, range: $0.3-10.5 \mathrm{mo}$ ) prior to their death were analyzed for associations with cognition. A significant positive correlation was observed between lutein concentrations in the cortex and the MMSE (global measure of cognitive function) and the Boston Naming Test (CERAD battery, a measure of language), while a negative correlation was observed with Geriatric Depression Scale $(P<0.05)$ (Table 6). The positive association of zeaxanthin in the cortex and verbal fluency was statistically significant $(P<0.05)$. $\alpha$-Tocopherol was positively associated with SIB (a global measure of cognitive function) and COWAT (a measure of executive function) $(P<0.05)$. In the case of retinol, there was a negative relation with FOME-delayed recognition $(P<0.05)$. No associations were observed with the other listed measures of cognitive function.

Carotenoids in the cerebellum were not associated with any of the cognitive function measures with the exception of a negative association between lutein and the Geriatric Depression Scale $(r=-0.63, P=0.005) . \alpha$-tocopherol in the cerebellum was positively associated with MMSE $(r=0.535$, $P=0.027)$ and SIB $(r=0.602, P=0.01)$, both of which are measures of global cognition.

\section{Discussion}

In this cross-sectional study involving octogenarians and centenarians, we found significant relationships between serum and brain concentrations of dietary carotenoids and various measures of cognitive function. No specific domain of the cognitive performance showed the strongest relationship with either serum or brain concentrations of carotenoids since significant relationships were observed with memory, executive function, and language. The fact that specific carotenoids were associated with more than one cognitive function and that these associations remained statistically significant after controlling for potential confounding factors supports a possible role for these phytonutrients in agerelated cognitive health. The present study is the first report on serum and brain carotenoids, $\alpha$-tocopherol, and retinol concentrations and their relationship to cognitive function in the oldest of the old. This is of importance given the dramatic increase in the number of Americans surviving into their 80s and 90 s and the increased prevalence of age-related cognitive diseases such as Alzheimer's disease [4].

Others have also found relationships with dietary carotenoids and age-related cognitive function. In crosssectional and longitudinal analysis of 442 subjects aged 65-94 years, Perrig et al. [45] reported that a higher $\beta$ carotene plasma level was associated with better memory performances (free recall, recognition, and vocabulary). In the Rotterdam Study of 5182 community participants aged 55-95 yrs, cross-sectional analysis found that a lower intake of $\beta$-carotene was associated with impaired cognitive function as measured by the MMSE [46]. In both of these studies, there were no significant relationships with vitamin E. Also, no other carotenoids were evaluated. Two studies have reported that supplementation with antioxidants including $\beta$-carotene $[47,48]$ reduces the risk of cognitive decline. However, given that both studies involved multivitamin/mineral supplementation, a specific effect of $\beta$-carotene is difficult to determine. In the EVA, a cross-sectional study using a variety of cognitive measures in 589 subjects $(68-79 \mathrm{yrs})$, it was found that those with the lowest cognitive functioning $(<25$ th percentile) had a higher probability of having low plasma levels of lycopene and zeaxanthin, but not lutein or $\beta$-carotene [49]. However, in a prospective study of older adults (mean age $73 \mathrm{y}$ ), Morris and colleagues found no association between $\beta$-carotene intake and risk of 
Alzheimer's disease [50]. Additionally, the Age-Related Eye Diseases Study Research Group [51] found no effect of a multivitamin/mineral supplementation which included $\beta$-carotene on MMSE score and a battery of cognitive measures in a population with a median age of $69 \mathrm{yrs}$. Rinaldi et al. found that plasma levels of lutein, zeaxanthin, and $\alpha$-carotene were lower in MCI and Alzheimer's disease subjects compared to controls but no difference for lycopene and $\beta$-carotene [10]. $\beta$-Cryptoxanthin was also significantly lower than controls in subjects with Alzheimer's disease but not in subjects with MCI. Others have reported lower levels of zeaxanthin, $\beta$-cryptoxanthin, lycopene, and $\beta$ carotene but not lutein and $\alpha$-carotene in Alzheimer's patients than in controls [52]. Inconsistencies among studies may be due to limited sample size, cognitive tests used, method of carotenoid assessment, or characteristics of the subject population. The major difference between our present study and previous research is the age of the population. In our population, the average age was $97 \mathrm{yrs}$ compared to averages of 67-77 yrs for the studies discussed above.

Whether a possible protective effect of carotenoids differs between the old and the oldest of the old remains to be tested. However, in our study, the most consistent relationships with cognition were observed for serum lutein, zeaxanthin, and $\beta$-carotene, reflecting diets rich in green leafy vegetables and orange and yellow vegetables such as carrots, sweet potatoes, and winter squash [53]. This remained to be true for the centenarians and with respect to living status, but only lutein remained significantly related to better measures of cognitive performance in the octogenarians. Furthermore, in brain tissue only concentrations of lutein and $\beta$-carotene were significantly lower in the cortex and cerebellum of subjects with MCI compared to those with normal cognitive function. Lutein and $\beta$-carotene may thus be important carotenoids for maintaining normal cognitive function in older adults. Consumption of vegetables, particularly the green leafy varieties that are rich sources of lutein and $\beta$ carotene, was associated with slower rates of cognitive decline in two large cohort studies $[5,8]$. Other evidence suggests that lutein supplementation, alone or in combination with docosahexaenoic acid, may be able to improve certain aspects of cognitive performance in healthy older women [22].

Although much recent work has focused on lutein and its role in ocular health [54], lutein was also the dominant carotenoid in various regions of the centenarian brains. On the contrary, carotenes ( $\alpha$-carotene, $\beta$-carotene, and lycopene) were predominant in serum, which more closely reflects dietary intake. These findings suggest that although not predominant in the diet, there seems to be a preferential uptake of lutein from the circulation into the brain. Craft et al. reported similar preferential uptake of xanthophylls in brain [23]. Trans isomers of lutein, zeaxanthin, cryptoxanthin and $\beta$-carotene, $\alpha$-tocopherol, and retinol were detected in all the brain tissues analyzed in this study. Only three cis isomers, two of lutein and one of $\beta$-carotene, were detected in the centenarian brain, which were not reported in the elderly brain tissues analyzed by Craft et al. [23]. Also, the ratios of cis to trans isomers in the brain were much lower than in serum, indicating a preferential uptake of trans isomers in the brain of these centenarians.

The majority of our findings find an association between lutein concentrations in serum or brain with age-related cognitive performance. However, there were significant associations for zeaxanthin and $\beta$-carotene as well. Therefore, the protective effect of carotenoids does not appear to be limited to the provitamin A carotenoids ( $\beta$-cryptoxanthin, $\alpha$-carotene, and $\beta$-carotene) nor to a class of carotenoids (xanthophylls versus carotenes). In addition, brain retinol levels were positively related to very few of the measures of cognition and negatively related to delayed recognition.

A protective effect of carotenoids may, in part, to be related to an antioxidant effect given that an antioxidant function is common to all carotenoids [55-58]. Furthermore, $\alpha$-tocopherol, a major dietary antioxidant, was found to be related to several measures of cognitive. Cortical carotenoids may be protective in nature and may also influence interneuronal communication and function via multiple mechanisms. Other mechanisms by which certain carotenoids may function include modulation of functional properties of synaptic membranes along with changes in their physicochemical and structural features [59]. Carotenoids have also been shown to enhance gap junctional communication [60] which in the retina is important for light processing and may be important for the development of neural circuitry in the visual system. Lutein and zeaxanthin, as macular pigments in the retina, have been related to increased visual processing speed and to reduced scotopic noise (noise associated with vision under dim light conditions) [61-63]. Lutein may also have antiinflammatory action in the brain, lowering inflammatory markers, and preventing cognitive decline [64, 65]. Neuroinflammation is also one of the factors that contribute to the pathogenesis of MCI and $\mathrm{AD}$ with increased levels of inflammatory markers being correlated with cognitive impairment [66].

The significant progressive decline in brain lutein and $\beta$ carotene with increased impairment from normal to MCI indicates that these carotenoids may play a role in preventing cognitive decline. MCI is thought to be the transitional stage between normal aging and the earliest symptoms of $\mathrm{AD}$. There may be as much as a $50 \%$ likelihood of individuals with MCI developing AD within five years [67]. Our finding of a significant decrease in lutein and $\beta$-carotene in subjects with MCI indicates that these carotenoids may play a role in maintenance of cognitive health prior to a decline to MCI. Future clinical studies should focus on nutritional interventions with lutein and $\beta$-carotene in subjects with MCI. Thus, far supplementation studies with $\beta$-carotene have yielded mixed results; the Physician Health Study II showed a long-term beneficial effect [68], while some studies showed no effect on cognitive function with $\beta$-carotene or antioxidant supplementation $[69,70]$. Effects of lutein supplementation on subjects with MCI have not been studied to date.

The strength of this study is that we were able to evaluate cognitive function in the elderly using a battery of cognitive tests that included the MMSE. This approach is more powerful than using only the less sensitive measure 
of MMSE. With the other tests, the scores ranges are wider, allowing for a better ability to study cognitive impairment. We were also able to evaluate cognitive relationships with a variety of dietary carotenoids using measures of serum concentrations. Carotenoid assessment using serum concentrations may be preferred to food frequency questionnaires because the high interindividual variation in intestinal bioavailability of carotenoids [71] does not need to be considered. Whether such variability exists for, uptake of carotenoids into brain tissue is not known. What is known is that the macular pigment response to supplementation of lutein from diet or supplements varies widely among individuals $[72,73]$. A variable response of uptake into the brain may also exist given the significant relationship between concentrations of xanthophylls in the retina and brain [26].

Thus, another strength of this study is the measures in brain tissue that are associated with premortem measures of cognition. Additionally, the strength of these cross-sectional relationships lies in the high interindividual variability in brain carotenoid concentrations, similar to that observed in the serum of these centenarians. Another strength of the study is that associations with cognitive function were evaluated with carotenoids, $\alpha$-tocopherol, and retinol actually embedded in brain tissue. However, the significant correlations between carotenoid concentrations in serum and brain tissue suggest that serum carotenoid measures could be a useful tool for evaluating the benefits of dietary carotenoids to age-related cognitive health.

One limitation to this study is that, in cross-sectional analysis, it is not possible to affirm whether these low levels of carotenoids preceded or were the consequence of cognitive impairment. Low carotenoid status, that is, poor food choices, may be a reflection of poor cognitive status. The significant relationships observed may not be due to specific effects of the individual carotenoids but, indication of overall healthier diets and lifestyles. Another limitation is that our analyses were performed in a sample drawn from a relatively small population. Therefore, we were unable to perform multivariate regression analysis that would have provided additional information regarding the independent contributions of the individual nutrient components.

\section{Conclusions}

In conclusion, this is the first study to evaluate the role of carotenoids, $\alpha$-tocopherol, and retinol in cognitive function in the oldest of the old. To date, previous studies evaluated older populations with average ages of 20-30 years younger than those of this study. Evaluations of the role of diet to health in this age group are becoming increasingly important given the rise in both life expectancy and the segment of the population who are $>80$ years. While far from conclusive, the idea that certain carotenoids can influence cognitive function is certainly feasible. The significance of our findings requires further research using biological studies, longitudinal epidemiological studies, and clinical trials with carotenoid supplementation.

\author{
Abbreviations \\ BMI: $\quad$ Body mass index \\ BDS: Behavioral Dyscontrol Scale \\ CERAD: Consortium to Establish a Registry for \\ Alzheimer's Disease \\ COWAT: Controlled Oral Word Association Test \\ FOME: Fuld Object Memory Evaluation \\ GCS: Georgia Centenarian Study \\ GDRS: Global deterioration rating scale \\ HPLC: High-performance liquid chromatography \\ MTBE: Methyl tert-butyl ether \\ MCI: Mild cognitive impairment \\ MMSE: Mini-Mental State Examination \\ MP: Macular pigment \\ SIB: $\quad$ Severe Impairment Battery \\ WAIS-III: Wechsler Adult Intelligence Scale-III.
}

\section{Acknowledgments}

The authors acknowledge the valuable recruitment and data acquisition effort from M. Burgess, K. Grier, E. McCarthy, L. Strong, and S. Reynolds, data acquisition team managers; S. Anderson, M. Janke, and T. Savla, data management; M. Poon, project fiscal management. Additional investigators in the Georgia Centenarian Study include Jonathan Arnold (University of Georgia), S. Michal Jazwinski (Tulane University Health Sciences Center), Peter Martin (Iowa State University), William R. Markesbery (deceased), Willard L. Rodgers (University of Michigan), Ilene C. Siegler (Duke University), and J. Lisa Tenover (Palo Alto VA Health Care System). The authors' responsibilities were as follows: $\mathrm{M}$. A. Johnson, L. W. Poon, designed the study; E. J. Johnson, A. Davey, L. S. Miller, J. L. Woodward, conducted and supervised the clinical research; R. C. Green, M. Gearing, P. T. Nelson, supervised brain donation, processing and storage; D. B. Hausman, coordinated inter-institutional agreements and sample transfer; R. Vishwanathan, L. T. M. Scott, H. Y. Chung, analyzed the data; R. Vishwanathan, E. J. Johnson and wrote the manuscript; R. Vishwanathan, E. J. Johnson interpreted data paper. All authors reviewed the paper; E. J. Johnson supervised the serum and brain analyses. R. Vishwanathan conducted the brain analysis. E. J. Johnson and R. Vishwanathan had equal contribution to the paper. None of the authors had a conflict of interests. This research was supported by USDA 58-1950-7-707, DSM Nutritional Products, and NIH 1P01-AG17553. Any opinions, findings, conclusions, or recommendations expressed in this are those of the author and do not necessarily reflect the view of the US Department of Agriculture.

\section{References}

[1] O. L. Lopez, W. J. Jagust, S. T. DeKosky et al., "Prevalence and classification of mild cognitive impairment in the cardiovascular health study cognition study," Archives of Neurology, vol. 60, no. 10, pp. 1385-1389, 2003. 
[2] Y. Gondo and L. W. Poon, "Cognitive function of Centenarians and its influence on longevity," Annual Review of Gerontology and Geriatrics, vol. 27, pp. 129-149, 2007.

[3] L. S. Miller, M. B. Mitchell, J. L. Woodard, A. Davey, P. Martin, and L. W. Poon, "Cognitive performance in centenarians and the oldest old: norms from the georgia centenarian study," Aging, Neuropsychology, and Cognition, vol. 17, no. 5, pp. 575590, 2010.

[4] Alzheimer's Association 2010 Alzheimer's Disease Facts and Figures, Alzheimer's Associaton National Office, Chicago, Ill, USA, 2010.

[5] M. C. Morris, D. A. Evans, C. C. Tangney, J. L. Bienias, and R. S. Wilson, "Associations of vegetable and fruit consumption with age-related cognitive change," Neurology, vol. 67, no. 8, pp. 13701376, 2006.

[6] L. Lee, S. A. Kang, H. O. Lee et al., "Relationships between dietary intake and cognitive function level in Korean elderly people," Public Health, vol. 115, no. 2, pp. 133-138, 2001.

[7] R. M. Ortega, A. M. Requejo, P. Andrés et al., "Dietary intake and cognitive function in a group of elderly people," American Journal of Clinical Nutrition, vol. 66, no. 4, pp. 803-809, 1997.

[8] J. H. Kang, A. Ascherio, and F. Grodstein, "Fruit and vegetable consumption and cognitive decline in aging women," Annals of Neurology, vol. 57, no. 5, pp. 713-720, 2005.

[9] J. H. Kang and F. Grodstein, "Plasma carotenoids and tocopherols and cognitive function: a prospective study," Neurobiology of Aging, vol. 29, no. 9, pp. 1394-1403, 2008.

[10] P. Rinaldi, M. C. Polidori, A. Metastasio et al., "Plasma antioxidants are similarly depleted in mild cognitive impairment and in Alzheimer's disease," Neurobiology of Aging, vol. 24, no. 7, pp. 915-919, 2003.

[11] J. N. Keller, F. A. Schmitt, S. W. Scheff et al., "Evidence of increased oxidative damage in subjects with mild cognitive impairment," Neurology, vol. 64, no. 7, pp. 1152-1156, 2005.

[12] E. Tarkowski, N. Andreasen, A. Tarkowski, and K. Blennow, "Intrathecal inflammation precedes development of Alzheimer's disease," Journal of Neurology, Neurosurgery and Psychiatry, vol. 74, no. 9, pp. 1200-1205, 2003.

[13] C. E. Teunissen, M. P. J. Van Boxtel, H. Bosma et al., "Inflammation markers in relation to cognition in a healthy aging population," Journal of Neuroimmunology, vol. 134, no. 1-2, pp. 142-150, 2003.

[14] M. J. Engelhart, M. I. Geerlings, J. Meijer et al., "Inflammatory proteins in plasma and the risk of dementia: the Rotterdam Study," Archives of Neurology, vol. 61, no. 5, pp. 668-672, 2004.

[15] M. A. Pappolla, M. A. Smith, T. Bryant-Thomas et al., "Cholesterol, oxidative stress, and Alzheimer's disease: expanding the horizons of pathogenesis," Free Radical Biology and Medicine, vol. 33, no. 2, pp. 173-181, 2002.

[16] T. Wyss-Coray, "Inflammation in Alzheimer disease: driving force, bystander or beneficial response?" Nature Medicine, vol. 12, no. 9, pp. 1005-1015, 2006.

[17] D. Praticò, “Alzheimer's disease and oxygen radicals: new insights," Biochemical Pharmacology, vol. 63, no. 4, pp. 563-567, 2002.

[18] D. Praticò and J. Q. Trojanowski, "Inflammatory hypotheses: novel mechanisms of Alzheimer's neurodegeneration and new therapeutic targets?" Neurobiology of Aging, vol. 21, no. 3, pp. 441-445, 2000.

[19] P. L. McGeer, E. G. McGeer, and K. Yasojima, "Alzheimer disease and neuroinflammation," Journal of Neural Transmission, Supplement, no. 59, pp. 53-57, 2000.
[20] G. Ravaglia, P. Forti, F. Maioli et al., "Homocysteine and folate as risk factors for dementia and Alzheimer disease," American Journal of Clinical Nutrition, vol. 82, no. 3, pp. 636-643, 2005.

[21] L. W. Poon, M. Jazwinski, R. Green et al., "Methodological consideration in studying centenarians: lessons learned from the Georgia Centenarian Studies," in Annual Review of Gerontology and Geriatrics, L. W. Poon and T. T. Perls, Eds., pp. 231-264, Springer, New York, NY, USA, 2007.

[22] E. J. Johnson, K. McDonald, S. M. Caldarella, H. Y. Chung, A. M. Troen, and D. M. Snodderly, "Cognitive findings of an exploratory trial of docosahexaenoic acid and lutein supplementation in older women," Nutritional Neuroscience, vol.11, no. 2, pp. 75-83, 2008.

[23] N. E. Craft, T. B. Haitema, K. M. Garnett, K. A. Fitch, and C. K. Dorey, "Carotenoid, tocopherol, and retinol concentrations in elderly human brain," Journal of Nutrition, Health and Aging, vol. 8, no. 3, pp. 156-162, 2004.

[24] E. J. Johnson, H. Y. Chung, S. M. Caldarella, and D. Max Snodderly, "The influence of supplemental lutein and docosahexaenoic acid on serum, lipoproteins, and macular pigmentation," American Journal of Clinical Nutrition, vol. 87, no. 5, pp. 15211529, 2008.

[25] J. H. Park, H. J. Hwang, M. K. Kim, and Y. C. Lee-Kim, "Con antioxidant vitamin status of the second generation rat brain sections," Korean Journal of Nutrition, vol. 34, pp. 754-761, 2001.

[26] R. Vishwanathan, M. Neuringer, D. M. Snodderly, W. Schalch, and E. J. Johnson, "Macular lutein and zeaxanthin are related to brain lutein and zeaxanthin in primates," Nutritional Neuroscience, vol. 16, no. 1, pp. 21-29, 2013.

[27] J. I. Sheikh and J. A. Yesavage, "Geriatric Depression Scale (GDS): recent evidence and development of a shorter version," Clinical Gerontologist, vol. 5, no. 1-2, pp. 165-173, 1986.

[28] M. F. Folstein, S. E. Folstein, and P. R. McHugh, “'Mini mental state. A practical method for grading the cognitive state of patients for the clinician," Journal of Psychiatric Research, vol. 12, no. 3, pp. 189-198, 1975.

[29] B. Reisberg, S. H. Ferris, M. J. De Leon, and T. Crook, “The global deterioration scale for assessment of primary degenerative dementia," American Journal of Psychiatry, vol. 139, no. 9, pp. 1136-1139, 1982.

[30] J. Saxton, K. L. McGonigle-Gibson, A. A. Swihart, V. J. Miller, and F. Boller, "Assessment of the severly impaired patient: description and validation of a new neuropsychological test battery," Psychological Assessment, vol. 2, no. 3, pp. 298-303, 1990.

[31] P. A. Fuld, Fuld Object Memory Evaluation Instruction Manual, Stoetling, Wood Dale, Ill, USA, 1981.

[32] D. Wechsler, Wechsler Adult Intelligence Scale-III, The Psychological Corporation, San Antonio, Tex, USA, 1997.

[33] J. Grigsby, K. Kaye, and L. J. Robbins, "Reliabilities, norms and factor structure of the Behavioral Dyscontrol Scale," Perceptual and Motor Skills, vol. 74, no. 3, pp. 883-892, 1992.

[34] A. Benton and K. Hamsler, Multilingual Aphasia Examination, University of Iowa, Iowa City, Iowa, USA, 1997.

[35] R. C. Atkinson and R. M. Shiffrin, "The control of short-term memory," Scientific American, vol. 225, no. 2, pp. 82-90, 1971.

[36] M. J. Chandler, L. H. Lacritz, L. S. Hynan et al., "A total score for the CERAD neuropsychological battery," Neurology, vol. 65, no. 1, pp. 102-106, 2005.

[37] K. A. Welsh-Bohmer and R. C. Mohs, "Neuropsychological assessment of Alzheimer's disease," Neurology, vol. 49, no. 3, pp. S11-S13, 1997. 
[38] K. Shaw, M. Gearing, A. Davey et al., "Successful recruitment of centenarians for post-mortem brain donation: results from the Georgia Centenarian Study," Journal of Bioscience and Medicine, vol. 2, no. 1, pp. 1-6, 2012.

[39] S. H. Ferris, T. Crook, C. Flicker, B. Reisberg, and R. T. Bartus, "Assessing cognitive impairment and evaluating treatment effects: psychometric performance test," in Handbook For Clinical Memory Assessment of Older Adults, L. S. Poon, Ed., pp. 139-148, American Psychological Association, Washington, DC, USA, 1986.

[40] R. Letz, NES2 User's Manual (version 4.4), Neurobehavioral Systems, Winchester, Mass, USA, 1991.

[41] B. Johansson and S. H. Sarit, "Early cognitive markers of the incidence of dementia and mortality: a longitudinal population based study of the oldest old," International Journal of Geriatric Psychiatry, vol. 12, pp. 53-59, 1997.

[42] M. Payton, K. M. Riggs, A. Spiro, S. T. Weiss, and H. Hu, "Relations of bone and blood lead to cognitive function: the VA normative aging study," Neurotoxicology and Teratology, vol. 20, no. 1, pp. 19-27, 1998.

[43] E. D. Bigler and D. F. Tate, "Brain volume, intracranial volume, and dementia," Investigative Radiology, vol. 36, no. 9, pp. 539546, 2001.

[44] V. Haroutunian, L. B. Hoffman, and M. S. Beeri, "Is there a neuropathology difference between mild cognitive impairment and dementia?" Dialogues in Clinical Neuroscience, vol. 11, no. 2, pp. 171-179, 2009.

[45] W. J. Perrig, P. Perrig, and H. B. Stähelin, "The relation between antioxidants and memory performance in the old and very old," Journal of the American Geriatrics Society, vol. 45, no. 6, pp. 718724, 1997.

[46] J. Warsama Jama, L. J. Launer, J. C. M. Witteman et al., "Dietary antioxidants and cognitive function in a populationbased sample of older persons: the Rotterdam study," American Journal of Epidemiology, vol. 144, no. 3, pp. 275-280, 1996.

[47] S. L. Gray, J. T. Hanlon, L. R. Landerman, M. Artz, K. E. Schmader, and G. G. Fillenbaum, "Is antioxidant use protective of cognitive function in the community-dwelling elderly?" American Journal Geriatric Pharmacotherapy, vol. 1, no. 1, pp. 3-10, 2003.

[48] A. Smith, R. Clark, D. Nutt, J. Haller, S. Hayward, and K. Perry, "Anti-oxidant vitamins and mental performance of the elderly," Human Psychopharmacology, vol. 14, pp. 459-471, 1999.

[49] N. T. Akbaraly, H. Faure, V. Gourlet, A. Favier, and C. Berr, "Plasma carotenoid levels and cognitive performance in an elderly population: results of the EVA Study," Journals of Gerontology A, vol. 62, no. 3, pp. 308-316, 2007.

[50] M. C. Morris, D. A. Evans, J. L. Bienias et al., "Dietary intake of antioxidant nutrients and the risk of incident Alzheimer disease in a biracial community study," Journal of the American Medical Association, vol. 287, no. 24, pp. 3230-3237, 2002.

[51] K. Yaffe, T. E. Clemons, W. L. McBee, and A. S. Lindblad, "Impact of antioxidants, zinc, and copper on cognition in the elderly: a randomized, controlled trial," Neurology, vol. 63, no. 9, pp. 1705-1707, 2004.

[52] P. Mecocci, M. Cristina Polidori, A. Cherubini et al., "Lymphocyte oxidative DNA damage and plasma antioxidants in Alzheimer disease," Archives of Neurology, vol. 59, no. 5, pp. 794798, 2002.

[53] http://fnic.nal.usda.gov/.
[54] D. M. Snodderly, "Evidence for protection against age-related macular degeneration by carotenoids and antioxidant vitamins," American Journal of Clinical Nutrition, vol. 62, no. 6, pp. 1448S-1461S, 1995.

[55] A. A. Woodall, G. Britton, and M. J. Jackson, "Carotenoids and protection of phospholipids in solution or in liposomes against oxidation by peroxyl radicals: relationship between carotenoid structure and protective ability," Biochimica et Biophysica Acta, vol. 1336, no. 3, pp. 575-586, 1997.

[56] A. A. Woodall, S. W. M. Lee, R. J. Weesie, M. J. Jackson, and G. Britton, "Oxidation of carotenoids by free radicals: relationship between structure and reactivity," Biochimica et Biophysica Acta, vol. 1336, no. 1, pp. 33-42, 1997.

[57] W. Stahl, A. Junghans, B. De Boer, E. S. Driomina, K. Briviba, and H. Sies, "Carotenoid mixtures protect multilamellar liposomes against oxidative damage: synergistic effects of lycopene and lutein," FEBS Letters, vol. 427, no. 2, pp. 305-308, 1998.

[58] W. Stahl and H. Sies, "Antioxidant activity of carotenoids," Molecular Aspects of Medicine, vol. 24, no. 6, pp. 345-351, 2003.

[59] W. I. Gruszecki, "Carotenoid orientation: role in membrane stabilization," in Carotenoids in Health and Disease, N. I. Krinsky, S. T. Mayne, and H. Sies, Eds., pp. 151-163, Marcel Dekker, New York, NY, USA, 2004.

[60] W. Stahl and H. Sies, "Effects of carotenoids and retinoids on gap junctional communication," BioFactors, vol. 15, no. 2-4, pp. 95-98, 2001.

[61] B. R. Hammond and B. R. Wooten, "CFF thresholds: relation to macular pigment optical density," Ophthalmic and Physiological Optics, vol. 25, no. 4, pp. 315-319, 2005.

[62] L. M. Renzi and B. R. Hammond, "The relation between the macular carotenoids, lutein and zeaxanthin, and temporal vision," Ophthalmic and Physiological Optics, vol. 30, no. 4, pp. 351-357, 2010.

[63] L. M. Renzi and B. R. Hammond, "The effect of macular pigment on heterochromatic luminance contrast," Experimental Eye Research, vol. 91, no. 6, pp. 896-900, 2010.

[64] S. B. Kritchevsky, A. J. Bush, M. Pahor, and M. D. Gross, "Serum carotenoids and markers of inflammation in nonsmokers," American Journal of Epidemiology, vol. 152, no. 11, pp. 1065-1071, 2000.

[65] E. J. Johnson, “Obesity, lutein metabolism, and age-related macular degeneration: a web of connections," Nutrition Reviews, vol. 63, no. 1, pp. 9-15, 2005.

[66] A. Schuitemaker, M. G. Dik, R. Veerhuis et al., "Inflammatory markers in $\mathrm{AD}$ and $\mathrm{MCI}$ patients with different biomarker profiles," Neurobiology of Aging, vol. 30, no. 11, pp. 1885-1889, 2009.

[67] Alzheimer's Association 2010 Alzheimer's Disease Facts and Figures, Alzheimer's Association National Office, Chicago, Ill, USA, 2010.

[68] F. Grodstein, J. H. Kang, R. J. Glynn, N. R. Cook, and J. M. Gaziano, "A randomized trial of beta carotene supplementation and cognitive function in men: the physicians' health study II," Archives of Internal Medicine, vol. 167, no. 20, pp. 2184-2190, 2007.

[69] J. H. Kang, N. R. Cook, J. E. Manson, J. E. Buring, C. M. Albert, and F. Grodstein, "Vitamin E, Vitamin C, Beta carotene, and cognitive function among women with or at risk of cardiovascular disease: the women's antioxidant and cardiovascular study," Circulation, vol. 119, no. 21, pp. 2772-2780, 2009. 
[70] A. B. Mendelsohn, S. H. Belle, G. P. Stoehr, and M. Ganguli, "Use of antioxidant supplements and its association with cognitive function in a rural elderly cohort: the movies project," American Journal of Epidemiology, vol. 148, no. 1, pp. 38-44, 1998.

[71] E. J. Johnson, "Human studies on bioavailability and serum response of carotenoids," in CRC Handbook of Antioxidants, E. Cadenas and L. Packer, Eds., pp. 265-277, Marcel Dekker, New York, NY, USA, 2nd edition, 2001.

[72] B. R. Hammond, E. J. Johnson, R. M. Russell et al., "Dietary modification of human macular pigment density," Investigative Ophthalmology \& Visual Science, vol. 38, pp. 1795-1801, 1997.

[73] E. J. Johnson, B. R. Hammond, K. J. Yeum et al., "Relation among serum and tissue concentrations of lutein and zeaxanthin and macular pigment density," American Journal of Clinical Nutrition, vol. 71, no. 6, pp. 1555-1562, 2000. 


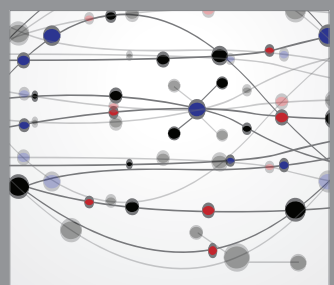

The Scientific World Journal
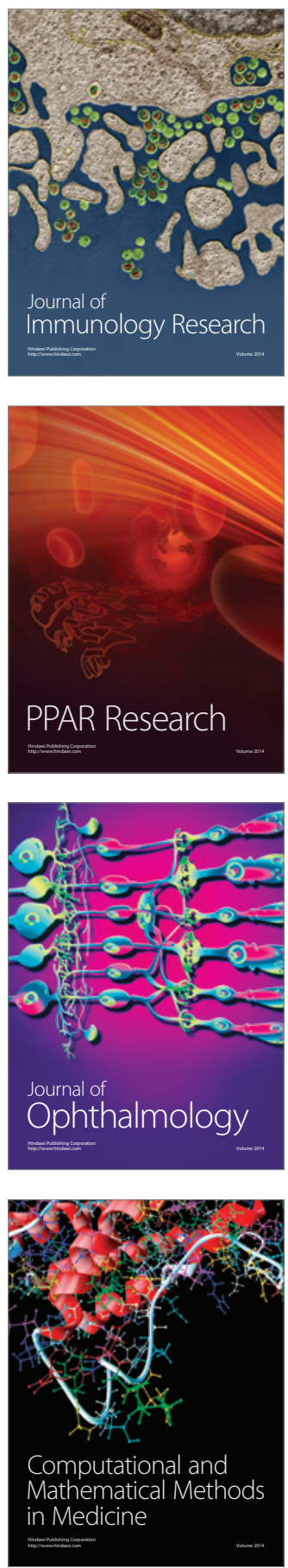

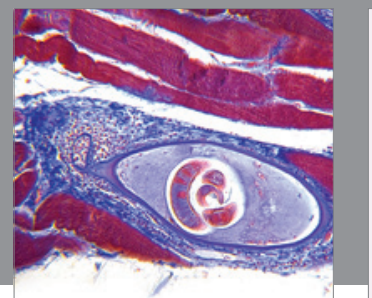

Gastroenterology

Research and Practice
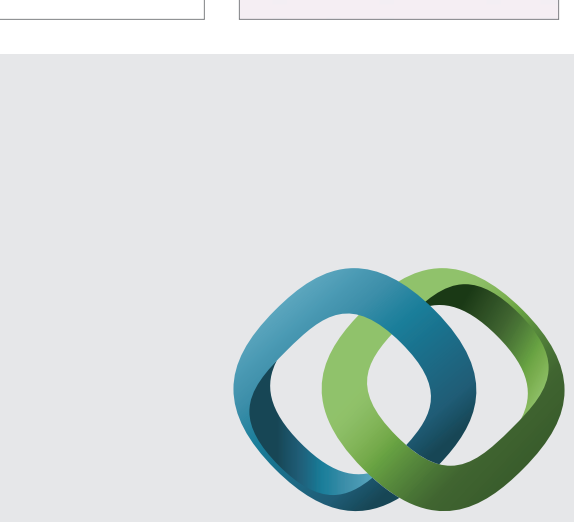

\section{Hindawi}

Submit your manuscripts at

http://www.hindawi.com
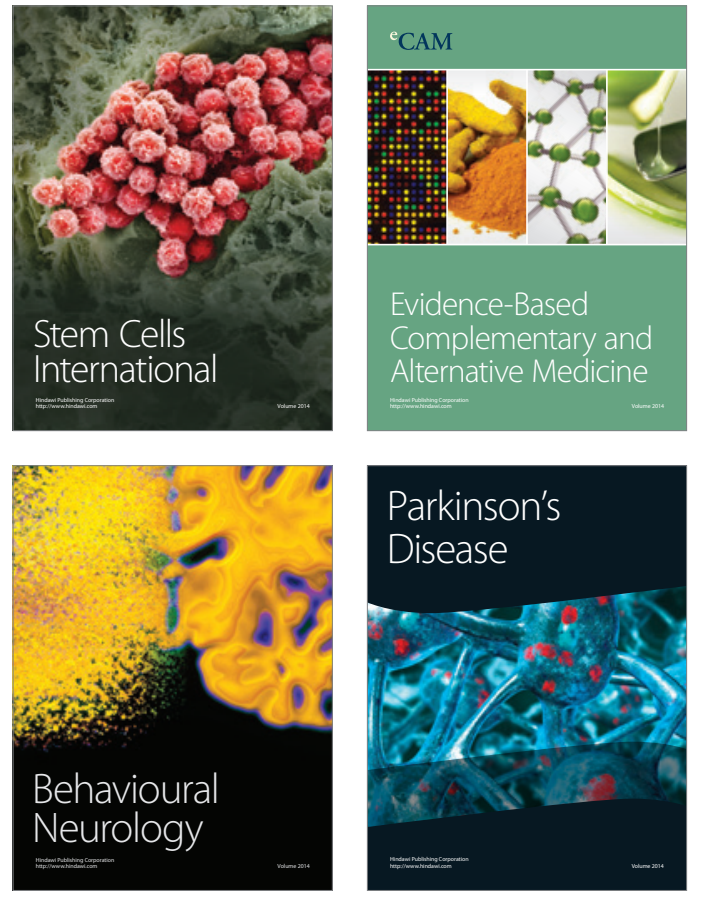
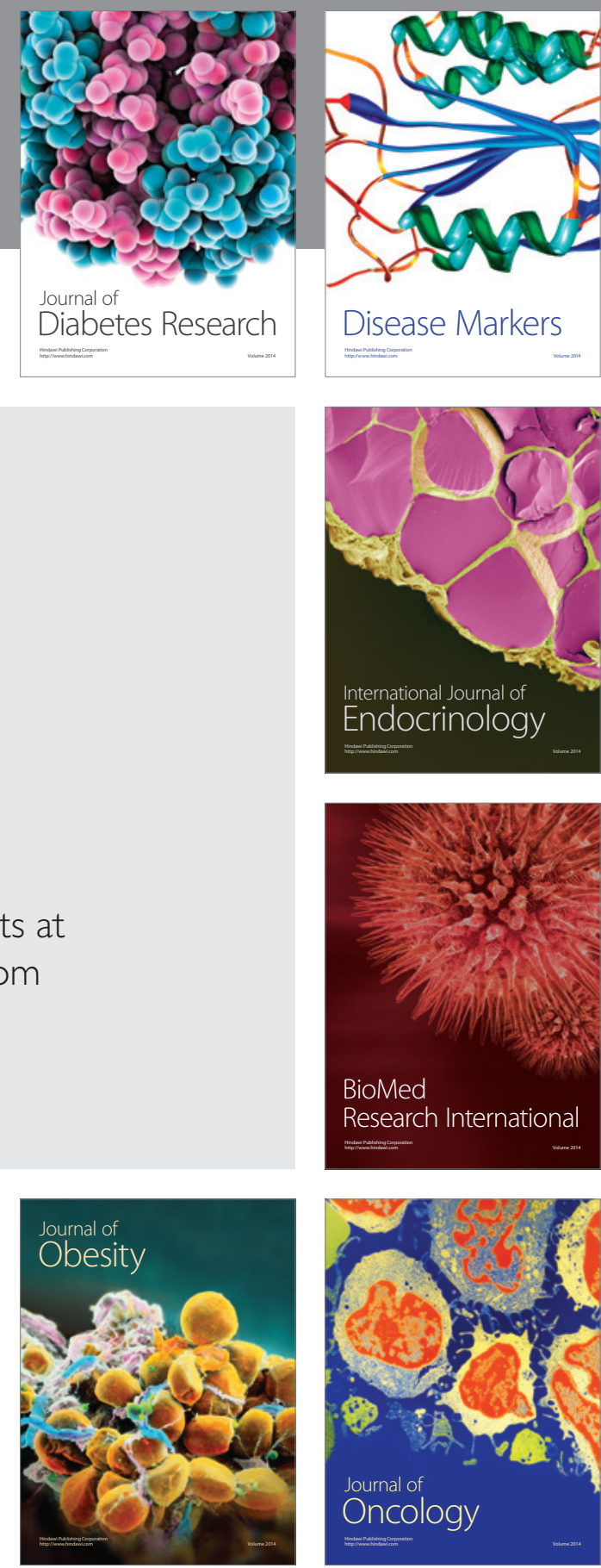

Disease Markers
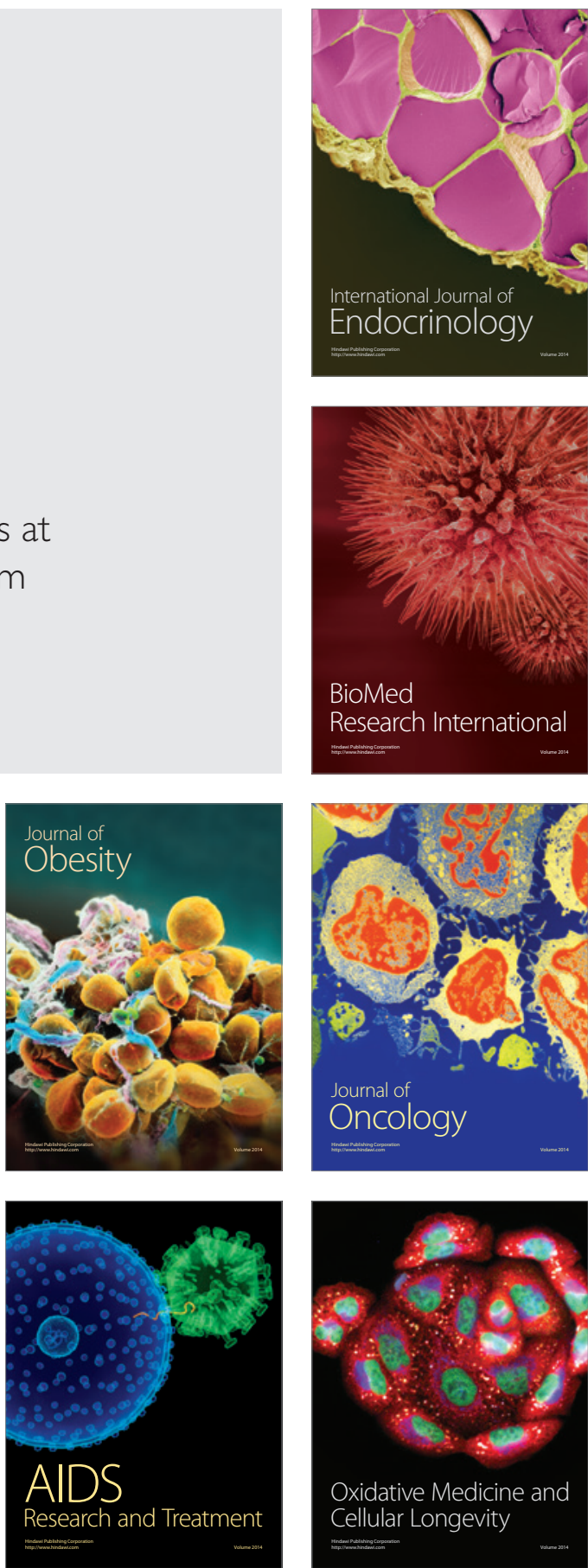